\title{
Pathogenesis of mild parkinsonian signs in aging
}

\author{
Kurt A. Jellinger
}

Received: 15 October 2014 / Accepted: 15 October 2014/Published online: 28 October 2014

(C) Springer-Verlag Berlin Heidelberg 2014

\section{Dear Sirs,}

In their recent study on the evolution of mild parkinson signs (MPS) in aging, Mahoney et al. [4], in a cohort of 210 healthy older adults, none of them demented, MPS were observed in $45 \%, 38 \%$ of whom were transient (mean age $75.8 \pm 7.37$ years), while $61 \%$ were persistent (mean age $79.8 \pm 7.15$ years). For the onset of MPS vascular mechanisms due to cardiovascular disease were suggested, and probably neurodegenerative mechanisms for the persistence of MPSs, while others suggested a multifactorial etiopathogenesis of MPS in the elderly [3]. Unfortunately, no neuropathologic findings were available in this study.

In an autopsy study of 160 elderly subjects (mean age $84.1 \pm 8.3$ SD years), $94.4 \%$ being demented, clinical MPS (rigidity, bradykinesia, flexed posture, frequent gait disorders, but almost no rest tremor) were reported in $21.9 \%$. Patients with MPS were slightly older than those without (mean age $86.7 \pm 66.6$ vs. $83.69 \pm 8.0$ SD years; difference not significant). Neuropathologic examination classified MPS + cases as "pure" AD without additional $\alpha$ synuclein ( $\alpha$ Syn) pathology (51\%), AD with incidental Lewy pathology (15\%), while early stages of PD or DLB were present in $33 \%$. MPS - cases included "pure" $\mathrm{AD}$ (74.6\%) and AD with incidental Lewy pathology (23\%), while none of both groups had a pathologic diagnosis of vascular or mixed type dementia [1]. MPS were only slightly more frequent in cases with higher neurofibrillary Braak stages. MPS correlated best with substantia nigra $(\mathrm{SN})$ cell loss $(p<0.001)$ and much less with $\alpha$ Syn

K. A. Jellinger $(\bowtie)$

Institute of Clinical Neurobiology, Kenyongasse 18,

1070 Vienna, Austria

e-mail: kurt.jellinger@univie.ac.at pathology in brainstem $(p<0.5)$. Although both pathologies in SN correlated with neuron loss $(\mathrm{p}<0.001)$, nigral tau lesions, present in $88.5 \%$ of MPS+ cases (without aSyn lesions in $55.6 \%$ ) did not correlate with MPS. Additional cerebrovascular changes did not influence the development of MPS symptoms. With other recent data [2, $5,6]$, these results suggest that neuronal loss in SN, partly related to tau pathology, is a major pathological substrate of MPS, at least in demented elderly subjects, although some patients with and without MPS may show no or only minimal nigral lesions. MPS in elderly patients may thus be a surrogate marker for severe neuritic AD pathology.

Conflicts of interest The author has no conflict of interest to disclose.

Ethical standard The manuscript does not contain clinical studies or patient data.

\section{References}

1. Attems J, Quass M, Jellinger KA (2007) Tau and $\alpha$-synuclein brainstem pathology in Alzheimer disease: relation with extrapyramidal signs. Acta Neuropathol 113:53-62

2. Liu Y, Stern Y, Chun MR, Jacobs DM, Yau P, Goldman JE (1997) Pathological correlates of extrapyramidal signs in Alzheimer's disease. Ann Neurol 41:368-374

3. Louis ED, Tang MX, Mayeux R (2004) Parkinsonian signs in older people in a community-based study: risk of incident dementia. Arch Neurol 61:1273-1276

4. Mahoney JR, Verghese J, Holtzer R, Allali G (2014) The evolution of mild parkinsonian signs in aging. J Neurol 261:1922-1928

5. Morris JC, Drazner M, Fulling K, Grant EA, Goldring J (1989) Clinical and pathological aspects of parkinsonism in Alzheimer's disease. A role for extranigral factors? Arch Neurol 46:651-657

6. Schneider JA, Li JL, Li Y, Wilson RS, Kordower JH, Bennett DA (2006) Substantia nigra tangles are related to gait impairment in older persons. Ann Neurol 59:166-173 